\section{Changes in Selected Quality Attributes of Greenhouse Tomato Fruit as Affected by Pre- and Postharvest Environmental Conditions in Year-round Production}

\author{
Chieri Kubota ${ }^{2}$ and Mark Kroggel \\ School of Plant Sciences, The University of Arizona, 303 Forbes Building, \\ Tucson, AZ 85721
}

\author{
Mohammad Torabi \\ University Information Technology Service, Research Data Center, The \\ University of Arizona, Tucson, AZ 85721
}

Katherine A. Dietrich, Hyun-Jin Kim ${ }^{1}$, and Jorge Fonseca

School of Plant Sciences, The University of Arizona, 303 Forbes Building, Tucson, AZ 85721

Cynthia A. Thomson

Department of Nutritional Sciences and Arizona Cancer Center, The University of Arizona, Tucson, AZ 85724

Additional index words. controlled environment, hydroponic, lycopene, soluble solids, TSS

Abstract. 'Durinta' tomatoes were grown hydroponically using rockwool substrate in greenhouses to assess the seasonal and postharvest changes of selected quality attributes including lycopene and total soluble solids (TSS, \% Brix) concentrations in fruit when grown under varied electrical conductivity (EC) in the nutrient solution. Two levels of EC examined in this study were 2.4 and $4.8 \mathrm{dS} \cdot \mathrm{m}^{-1}$ for standard low EC and high EC treatments, respectively. All fruits at light-red and red ripeness stages were harvested and weighed every week, and nine fruits visually representing the median group of red fruits were selected from each EC treatment and subject to measurements of lycopene and TSS concentrations. Of 53 harvest weeks (Dec. 2005 to Dec. 2006), 45 weeks were subject to fruit quality analyses at harvest and 3 weeks were subject to postharvest quality analyses. Lycopene concentration and TSS showed seasonal differences with larger variation in lycopene, but the high EC treatment induced an overall average of $18 \%$ greater lycopene concentration and a $20 \%$ greater TSS. The regression analyses indicated that efflux solution EC (EEC) was the most influential factor for both lycopene and TSS concentrations, but secondary influential factors were greenhouse temperature for lycopene and daily light integral for TSS. Postharvest storage test showed that selected fruit quality attributes (lycopene, TSS, ascorbic acid, and total phenolics) changed minimally or not at all for 10 days when stored at $12{ }^{\circ} \mathrm{C}$, a widely recommended tomato postharvest storage temperature. Overall, we consider that producing lycopenerich tomato by controlling EC of nutrient solution was feasible during year-round greenhouse production using a high-wire rockwool culture system.

Greenhouse-controlled environment technology was traditionally developed to extend the crop cycle into seasons that are too harsh to produce crops in open fields. The technology has focused on optimizing environmental conditions to maximize yield as well as

Received for publication 13 Aug. 2012. Accepted for publication 24 Sept. 2012.

This research was funded by Bio5, the University of Arizona Institute for Collaborative BioResearch. We acknowledge the in-kind support provided by UA CEAC and Western Seeds.

${ }^{1}$ Current address: Korea Food Research Institute, 1201-62 Anyangpangyo-ro, Bundang-gu, Seongnamsi, Gyeonggi-do 463-746, Republic of Korea.

${ }^{2}$ To whom reprint requests should be addressed; e-mail ckubota@ag.arizona.edu. also the predominant food crop produced in North American greenhouses. The successful development of large-scale greenhouse tomato growers with year-round production capacity and consistent high-quality product has resulted in favorable purchasing of greenhouse produce by U.S. retail stores. Nearly $40 \%$ of tomatoes available in U.S. retail stores were reportedly from North American greenhouses (Cook and Calvin, 2005).

Compared with the remarkable achievement in increasing yield and market acceptance of greenhouse tomato, it seems that improving organoleptic and/or nutritional quality of the fruit has received less emphasis in North American greenhouse industries, although flavor of nutrient-rich tomatoes has been ranked high in consumer surveys for purchasing decision factors (Weaver et al., 1992). Furthermore, flavor and nutritional quality are considered as "experiencebased quality attributes" (Wismer, 2009) that would affect the consumer decision for continued consumption, especially when the quality attribute can be associated with branding (packaging and logos) to identify the specific product and source.

Overall flavor of tomato fruit is commonly evaluated using TSS estimated using a refraction index (Brix) as an indicator. Sugar and organic acids are important flavor components in tomato fruit and measurements of refraction index are affected by sugars predominantly and also by organic acids (Saltveit, 2005). It is therefore generally accepted that tomato fruit with greater TSS is more flavorful. Total soluble solid concentration is affected by water content in fruit and can be increased by limiting water transport to the fruit by growing the plant under lower (more negative) water potential in the root zone. Based on this understanding, growing tomato plants hydroponically using nutrient solution with high EC has been commercially practiced worldwide, yet to a limited extent in North America (Buck et al., 2008).

Lycopene is an antioxidant abundant in tomato that reportedly helps to reduce oxidative stress (Kelkel et al., 2011) and thus, indirectly, oxidative-stress associated disease such as cardiovascular diseases and cancer in the human body (Böhm, 2012; Tanaka et al., 2012). Several environmental factors reportedly can affect lycopene concentration in tomato fruit. Salt stress has been shown to accelerate the lycopene development in fruit (on both a fresh and dry weight basis) when tomato plants were grown hydroponically using nutrient solution containing high EC $\left(4.5 \mathrm{dS} \cdot \mathrm{m}^{-1}\right.$ EC) (Wu and Kubota, 2008). These results suggest that growing tomato plants under high EC could be developed into a commercial technique to improve both flavor and health-promoting attributes of fresh fruit (Kubota et al., 2006).

Validating a new cultivation technique in year-round production is crucial to implement the technology in a commercial setting. Previous studies revealed that there are factors that influence lycopene synthesis, 
including temperature (e.g., Krumbein et al., 2006) and light intensity (e.g., Dumas et al., 2003), both of which widely change diurnally and seasonally in greenhouse. It is also important to understand the potential change in lycopene concentration and other fruit quality attributes during postharvest storage. Postharvest changes in tomato fruit quality have been extensively studied, including concentrations of carotenoids (Giovanelli et al., 1999; Javanmardi and Kubota, 2006; Liu et al., 2009; Toor and Savage, 2006), TSS (Javanmardi and Kubota, 2006; Liu et al., 2009; Wills and $\mathrm{Ku}, 2002$ ) and other healthpromoting compounds such as ascorbic acid and phenolic compounds (Giovanelli et al., 1999; Toor and Savage, 2006). However, interactions of preharvest conditions (such as EC) and postharvest conditions (such as storage temperature) are not well quantified.

We conducted a year-round production study to evaluate the technique of producing tomato rich in lycopene and flavor under increased EC of the nutrient solution in a high-wire production system similar to commercial greenhouses. The postharvest changes in lycopene and other quality attributes in fruit produced under high and low EC during storage at different air temperatures were quantified. This study was conducted as part of the diet intervention study designed and reported by Thomson et al. (2008) wherein the health-promoting efficacy of tomatoes grown under increased EC was examined. Therefore, some experimental procedures used in this present study were selected to satisfy the requirements of this human health study.

\section{Materials and Methods}

Greenhouse tomato production. 'Durinta' tomato plants were grown in a high-wire system (3.5 m height) using rockwool substrate in two identical greenhouses $\left(280-\mathrm{m}^{2}\right.$ floor area, standing side by side separated by $9.2 \mathrm{~m}$ in distance) with an arc roof covered with air-inflated double-layer polyethylene film located at the University of Arizona (Tucson, AZ). The height from the ground to the roof peak and gutter were $6.3 \mathrm{~m}$ and $4.0 \mathrm{~m}$, respectively. The global light transmission of the greenhouse was $\approx 70 \%$ as daily average except during the time a $50 \%$ shade screen installed at the gutter height was deployed (Ludvig Svensson, Charlotte, NC) when air temperature exceeded $29{ }^{\circ} \mathrm{C}$ inside the greenhouse or the outside solar radiation exceeded $750 \mathrm{~W} \cdot \mathrm{m}^{-2}$.

The target day and nighttime air temperatures and vapor pressure saturation deficit (VPD) were set at $24{ }^{\circ} \mathrm{C}, 18{ }^{\circ} \mathrm{C}$, and $1.0 \mathrm{kPa}$, respectively, using a greenhouse environment controller (Argus Control Systems, White Rock, British Columbia, Canada). Actual air temperatures and VPD inside the greenhouse varied as shown in Figure 1 influenced by outside climate conditions as well as evapotranspiration inside the greenhouse. A fan-and-pad evaporative cooling system and an overhead heating system
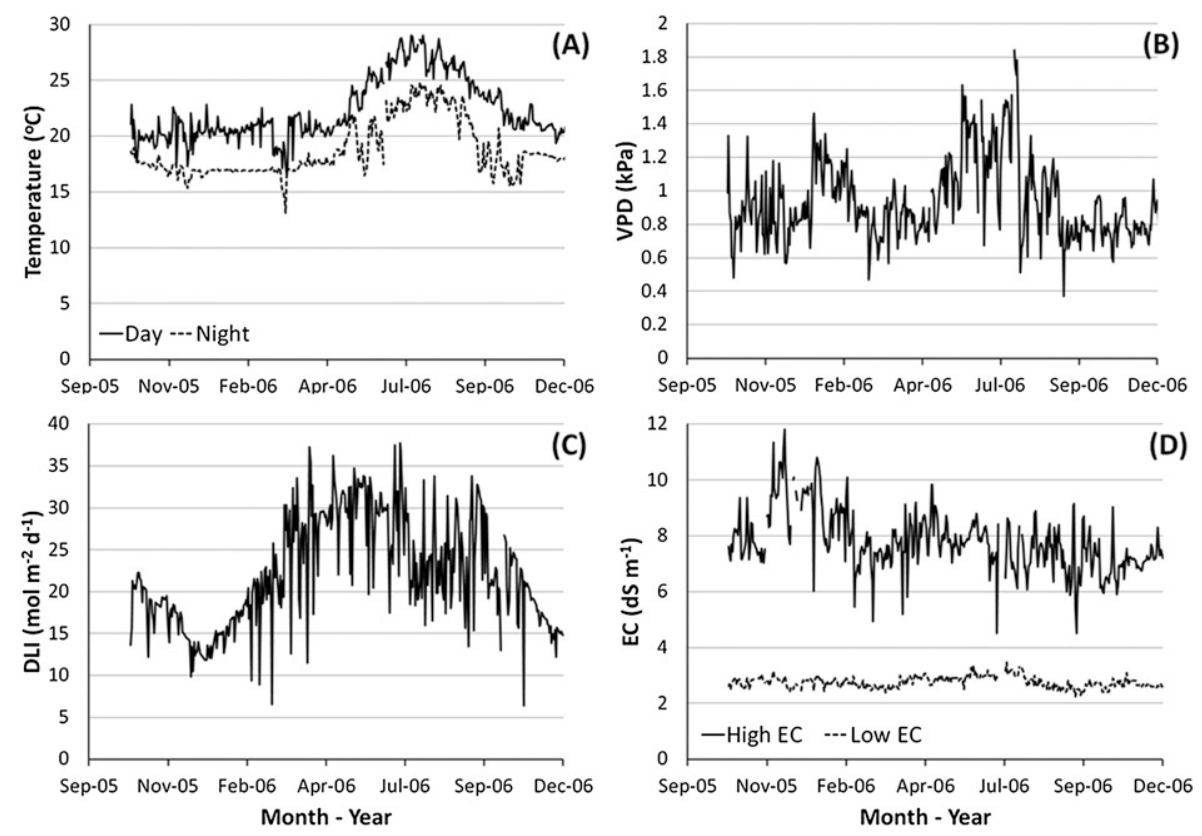

Fig. 1. Greenhouse environment conditions during the experiment. (A) Daily mean daytime and nighttime air temperatures $\left({ }^{\circ} \mathrm{C}\right),(\mathbf{B})$ daily mean daytime vapor pressure saturation deficit $(\mathrm{VPD}, \mathrm{kPa}),(\mathbf{C})$ daily mean daily light integral $\left(\mathrm{DLI}, \mathrm{mol} \cdot \mathrm{m}^{-2} \cdot \mathrm{d}^{-1}\right)$, and (D) electrical conductivity of the efflux nutrient solution $\left(\mathrm{EEC}, \mathrm{dS} \cdot \mathrm{m}^{-1}\right)$.

(Modine, Racine, WI) were used for air temperature control. A high-pressure fogging system (Valco, Bird-in-Hand, PA) was used to maintain VPD during the day. Carbon dioxide concentration was not controlled in these greenhouses.

In addition to the environment controller, we set up a series of sensors in the center location of each greenhouse for more accurately recording of 1) photosynthetic photon flux $(P P F)$ using a quantum sensor (Apogee Instrument, Logan, UT) over the plant canopy; and 2) air temperature and relative humidity inside the canopy using an aspirated and shielded probe (CS500L; Campbell Scientific, Logan, UT). Sensors were connected to a Campbell data logger (CR23X) and their outputs were scanned every $10 \mathrm{~s}$ to average every $15 \mathrm{~min}$. $P P F$ was then totalized for each day for computing daily photosynthetic light integral $\left(\mathrm{DLI}, \mathrm{mol} \cdot \mathrm{m}^{-2} \cdot \mathrm{d}^{-1}\right)$. Relative humidity was converted to VPD $(\mathrm{kPa})$ at the corresponding temperature.

The fertigation system was a top-fed drip irrigation system with pressure-compensated emitters (flow rate: $2 \mathrm{~L} \cdot \mathrm{h}^{-1}$ ). Styrofoam blocks $15 \mathrm{~cm}$ high were placed under the plastic gutter holding the rockwool slabs to elevate the gutter and to assist with drainage of the nutrient solution. The basal composition of the nutrient solution contained the following elements in $\mathrm{mg} \cdot \mathrm{L}^{-1}: 190$ nitrogen (N) (all in $\mathrm{NO}_{3}-\mathrm{N}$ ), 47 phosphorus, 350 potassium (K), 200 calcium, 60 magnesium, 2 iron, 0.6 manganese, 0.3 zinc, 0.05 copper, 0.4 boron, and 0.05 molybdenum with some modifications mainly to achieve lower concentrations of $\mathrm{N}$ (90 to $120 \mathrm{mg} \cdot \mathrm{L}^{-1}$ ) and $\mathrm{K}$ $\left(144 \mathrm{mg} \cdot \mathrm{L}^{-1}\right)$ during the early vegetative growth stage. EC of the nutrient solution was either at 2.4 (standard, low EC) or 4.8 $\mathrm{dS} \cdot \mathrm{m}^{-1}$ (high EC). The higher EC was achieved by adding $957 \mathrm{mg} \cdot \mathrm{L}^{-1} \mathrm{NaCl}$ and $32 \mathrm{mg} \cdot \mathrm{L}^{-1} \mathrm{CaCl}_{2}$ to the basal solution following the procedure of $\mathrm{Wu}$ and Kubota (2008). The $\mathrm{pH}$ of the nutrient solution was adjusted to 6.0 for both EC solutions by adding nitric acid. Irrigation frequency was every 15 to 30 min during the day using a programmable timer but the amount of nutrient solution irrigated per event was $100 \mathrm{~mL}$ per plant. The frequency was adjusted using a programmable irrigation timer so as to achieve target EC 2.5 to $3.0 \mathrm{dS} \cdot \mathrm{m}^{-1}$ and 7.0 to $9.0 \mathrm{dS} \cdot \mathrm{m}^{-1}$ in the efflux nutrient solution for low and high EC settings, respectively. Volume, $\mathrm{pH}$, and EC of the inflow to plants and the efflux nutrient solution drained from the rockwool slabs were recorded daily using a simple lysimeter setup for four locations inside the greenhouse (two for each EC treatment). Handheld EC and pH meters (Hanna Instruments, Woonsocket, RI) were used and calibrated weekly.

Seeds were sown into a sheet of Grodan rockwool plugs $(4 \mathrm{~cm} \times 4 \mathrm{~cm} \times 4 \mathrm{~cm})$ and transplanted into larger cubes $(10 \mathrm{~cm} \times$ $10 \mathrm{~cm} \times 10 \mathrm{~cm}$ ) when two true leaves were fully expanded. The seedlings were then grown for 2 to 3 weeks until transplanted onto the rockwool slabs $(20 \mathrm{~cm} \times 100 \mathrm{~cm} \times 6 \mathrm{~cm})$ at a density of six plants per slab (three sets of two side-by-side plants) in north-southoriented rows (three plants $/ \mathrm{m}^{2}$ plant density over the plant growing area in the greenhouse). All plants were trained to have a single stem. Common greenhouse plant maintenance practiced for high-wire cultivation system, including leaf pruning, 
removing side shoots, vine-training, and adjusting canopy height was conducted on a weekly basis. Fruits were pruned to four per truss for plants grown under high EC and six per truss for plants grown under low EC to produce similar sized fruits regardless of EC levels, a requirement of the diet intervention study concurrently conducted using the tomato fruits (Thomson et al., 2008).

Pests were controlled biologically, periodically introducing commercial products containing parasitic wasps (Encarsia formosa Gohan) for whitefly (Trialeurodes vaporariorum Westwood) and applying sulfur dust for russet mites (Aculops lycopersici Massee). However, twice during the experiment, we had to introduce non-biological pesticide abamectin (Syngenta Crop Protection, Greensboro, NC) for controlling russet mites when immediate control was needed. Bumblebees (Koppert Biological System Inc., Romulus, MI) were introduced to promote pollination.

Experiment was conducted using four crops transplanted on 22 Apr. 2005, 6 Sept. 2005, 10 Feb. 2006, and 8 Aug. 2006 and the harvest of fruit used for the present experiment began on 3 Dec. 2005 (nearly the end of first crop) and ended on 6 Dec. 2006 (a total of 53 harvest weeks), of which 45 harvest weeks were subject to fruit quality analysis. Use of the two identical greenhouses was alternating so that when a new crop in one house started producing harvestable fruits, the old crop was removed from the other to be replanted with seedlings to start over. There were 420 plants in each greenhouse. Half of the plants were grown under standard low EC and the other half were grown under high EC. A double row of 36 plants (length: $6.7 \mathrm{~m}$ ) was considered as a replication and there were two replications per EC treatment in each of north and south sections of the greenhouse (total of 144 plants per treatment). High and low EC treatment rows were arranged as alternating rows in the greenhouse. In addition to the experimental rows, there was one single row (three plants per slab) along the east and west side walls and one additional rockwool slab with six plants per row at the north and south ends of the entire canopy. These additional plants were considered as guard plants to protect the experimental plants from possible edge effects caused by the drastic change in microclimate and were not included in the analysis.

Once a week, all fruits at light-red and red ripeness stages were harvested, counted, and sorted by weight and overall color. Nine uniform fruits weighing 100 to $130 \mathrm{~g}$ and visually representing the median group of red fruits were selected from each EC treatment for fruit quality analysis. The remaining fruits in the same weight range were used for another study (diet intervention study reported by Thomson et al. 2008), except those used for postharvest tests described below.

Postharvest quality test. On 24 Oct. 2005, 10 Mar. 2006, and 28 Aug. 2006, uniform fruits at the red stage were selected and placed blossom-end side up in a single layer inside cardboard produce boxes and stored in the dark inside one of three growth chambers controlled at 4,12 , and $20^{\circ} \mathrm{C}$. A total of 218 fruits were used in one experiment (36 fruits of each EC treatment stored at each temperature; 654 fruits in total for three harvests). Nine tomatoes from each EC treatment stored at each temperature were randomly selected on $0,3,7$, and $10 \mathrm{~d}$ in storage and subject to fruit quality analyses.

Fruit quality analysis. Fruits sampled from postharvest quality test were analyzed immediately after removal from the storage. Other fruits sampled weekly over the year were stored overnight at $4{ }^{\circ} \mathrm{C}$ and subject to the analysis of lycopene and TSS. The nine fruits were randomly separated into three groups of three fruits, which were pureed together for analysis of lycopene and TSS. Extraction and quantification of lycopene in the fruit followed the method described by Fish et al. (2002) and Wu and Kubota (2008). TSS in juice was determined by a handheld refractometer (PR-32 $\alpha$; ATAGO USA, Kirkland, WA) and the measured values were corrected to a standard temperature condition of $20^{\circ} \mathrm{C}$. After measuring lycopene and TSS concentrations, the remaining puree was freeze-dried and stored at $-80{ }^{\circ} \mathrm{C}$ for further analyses. Freeze-dried samples were shipped to the University of Arizona Yuma Agricultural Center for analyses of total phenolics compounds and ascorbic acid (vitamin C). The analytical methods for total phenolics compounds (gallic acid equivalent) and ascorbic acid concentrations followed the methods described by Kim et al. (2007).

Statistical analyses. Statistical analyses applied to greenhouse environments, lycopene concentration, and TSS included analysis of variance (ANOVA), Pearson's correlation analysis, and a stepwise regression analysis using the SPSS Statistical Package (V20.00; IBM, Armonk, NY). The postharvest experiment was replicated over time. ANOVA was applied for storage fruit quality data using JMP software (SAS Institute, Cary, NC). Selection of fruits used for postharvest was randomly performed from all the greenhouse replications of each EC treatment.

\section{Results and Discussion}

Greenhouse environments. Greenhouse environmental conditions (16 Oct. 2005 to 6 Dec. 2006) are shown in Figure 1. Daily averaged daytime air temperature was in the range of 16.5 to $22.8{ }^{\circ} \mathrm{C}$ during October to mid-May, and it exceeded $25{ }^{\circ} \mathrm{C}$ during the summer (June to September) as a result of an increase in solar radiation and wetbulb temperature, reducing the greenhouse's evaporative cooling efficiency. Daily averaged nighttime temperature followed the trend of seasonal changes in daytime temperature and maintained an average of $3.5^{\circ} \mathrm{C}$ day-nighttime temperature difference (maximum $7.8^{\circ} \mathrm{C}$ ). Average daytime VPD ranged from 0.4 to $1.8 \mathrm{kPa}$. The highest DLI over the plant canopy was $37.8 \mathrm{~mol} \cdot \mathrm{m}^{-2}$ on $2 \mathrm{July}$
2006. The relatively low DLI during July to early September was the result of more extended use of $50 \%$ shadecloth to maintain the air temperature inside the greenhouse. The DLI during winter was greater than $10 \mathrm{~mol} \cdot \mathrm{m}^{-2}$ except for a few exceptionally overcast days in February and October (the lowest DLI recorded was $6.5 \mathrm{~mol} \cdot \mathrm{m}^{-2}$ ).

EEC fluctuated widely in the high EC treatment $\left(4.5\right.$ to $\left.11.8 \mathrm{dS} \cdot \mathrm{m}^{-1}\right)$ with an overall average of $7.8 \pm 0.9 \mathrm{dS} \cdot \mathrm{m}^{-1}( \pm \mathrm{SD})$. The fluctuations in EEC are caused by plant water and nutrient uptake and irrigation rate. We found that this EEC management would be the most difficult part in the cultivation techniques under high EC; however, we consider that EEC more closely represents the EC within the slab and therefore more directly affects the plant responses than EC of influx nutrient solution. By using an integrated computer control, the irrigation frequency could be decided based on cumulative solar radiation over the canopy, and EEC could have been managed in a narrower range. In contrast, EEC was relatively well maintained in the low EC treatment $(2.3$ to $3.5 \mathrm{dS} \cdot \mathrm{m}^{-1}$ with average $2.8 \pm 0.2 \mathrm{dS} \cdot \mathrm{m}^{-1}$ ) $( \pm \mathrm{SD})$ in the present experiment. This was because we intentionally increased the irrigation frequency of low EC treatment to maintain a distinctly low EEC compared with that of high EC treatment.

Seasonal changes in lycopene concentration, total soluble solids, and weekly yields. Lycopene concentrations (fresh weight basis) (Fig. 2) widely fluctuated in both high EC and low EC treatments. There were several harvest weeks when significant differences in lycopene concentration between the treatments were not detectable, but overall ANOVA showed that fruit under high EC had significantly higher lycopene concentrations (overall average: $\left.56.8 \pm 1.1 \mathrm{mg} \cdot \mathrm{kg}^{-1}\right)($ mean $\pm \mathrm{SE}$ are shown hereafter, unless otherwise stated) than those under low EC $\left(48.3 \pm 0.9 \mathrm{mg} \cdot \mathrm{kg}^{-1}\right)$ $(P<0.0001)$.

TSS (Fig. 2) was significantly higher under high EC (overall average $4.9 \pm 0.08 \%$ Brix) than low EC $(4.1 \pm 0.05 \%$ Brix $)(P<$ $0.0001)$. The TSS was relatively higher during early spring than that during the rest of year, showing that TSS was affected not only by water potential in the root zone, but also by the greenhouse environment conditions. Similarly, increase in TSS by increasing nutrient concentration as well as salt concentrations was reported by Adams (1991), Buck et al. (2008), Dorais et al. (2001) and Krauss et al. (2006). Buck et al. (2008) also showed that seasonal changes in TSS were caused by the seasonal changes in greenhouse environments.

Throughout the experiment, there was only negligible amount of blossom-end rot observed in fruit and no other fruit developmental disorder was noted. Weekly harvest yields fluctuated widely (data not shown) (as a result of the changes in greenhouse environments as well as the difference between the biological developmental cycle and our harvest schedule). Therefore, we averaged 
weekly harvest for each month during the experiment. The monthly averages of weekly yield (Fig. 3) peaked in May to July and were low in midwinter to early spring (December to March) and in the fall (September to October). The shift in peak production to the season during which the greenhouse environmental conditions were not necessarily optimum (for example, unfavorably high air temperature occurred during July to September, whereas the anticipated resulting low production period did not appear until September) could be supported by Higashide (2009) who found that the weekly yields of tomato were most highly correlated to the greenhouse environmental conditions during or several days before anthesis.
Our earlier study using the same cultivar (Wu and Kubota, 2008) reported no significant reduction in yield by high $\mathrm{EC}$ treatment $\left(4.5 \mathrm{dS} \cdot \mathrm{m}^{-1}\right)$. The greater yield in low EC treatment than high EC in the present experiment was mainly because there were more fruit per truss in low EC treatment. As stated earlier, two more fruits were left per truss in low EC treatment than high EC treatment to control the fruit size (overall average $102 \pm$ 19.6 and $107 \pm 19.7 \mathrm{~g}$ per fruit for high and low EC, respectively), but this practice may have altered sink-source relationships particularly during spring and early summer when the greater DLI and optimal greenhouse environments were present to support the source strength, creating a large difference
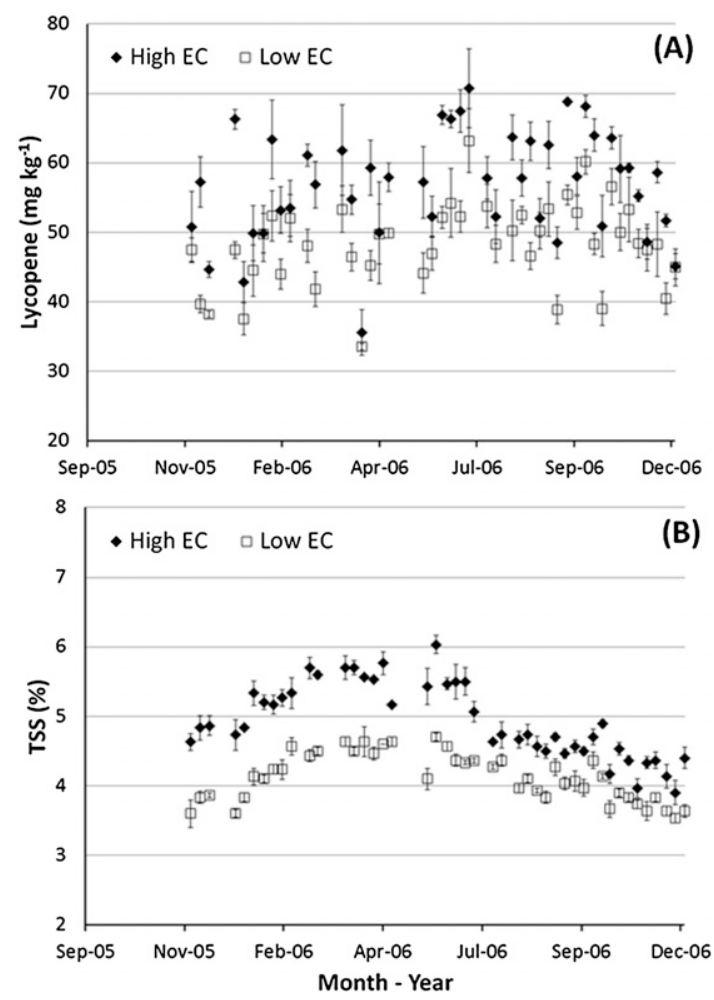

Fig. 2. Lycopene concentration (mg. $\mathrm{kg}^{-1}$ fresh weight) and total soluble solid concentration (Brix, \%) of fruit during the experiment. Fruits were sampled for 45 harvest weeks out of the total of 53 harvest weeks. Means $\pm \mathrm{SE}(\mathrm{n}=3)$ are shown.

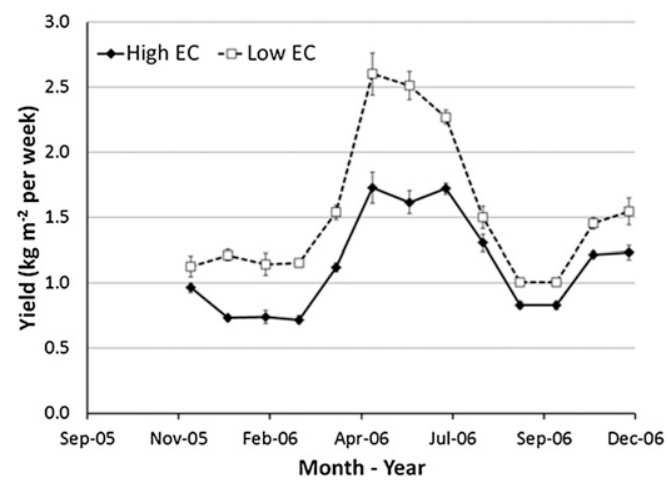

Fig. 3. Monthly average of weekly yield $\left(\mathrm{kg} \cdot \mathrm{m}^{-2}\right.$ per week) during the experiment. Means $\pm \mathrm{SE}(\mathrm{n}=4)$ are shown.

in yield between low and high EC treatments in these seasons.

Lycopene concentration and total soluble solids as affected by greenhouse environmental conditions. Table 1 shows the correlations between lycopene concentration, TSS, DLI, daytime air temperature (DT), daytime VPD, and EEC. Environmental data were used as a 4-week running average to correlate with changes in lycopene and TSS of the fruits harvested in selected weeks (45 of 53 harvest weeks). The duration of running average (4 weeks before harvesting) was decided based on the change in lycopene and TSS in fruit after anthesis (Wu and Kubota, 2008). Pearson's correlation analysis between environmental variables (data not shown) showed that nighttime temperature (NT) was highly correlated with DT (Pearson's correlation coefficient, $r=0.954, P<0.0001)$ and therefore NT was excluded from the regression analyses. All four environmental variables showed significant positive correlations with lycopene concentration in fruit, whereas three variables, DLI, VPD, and EEC showed significant positive correlations with TSS, respectively. There was also a positive correlation between lycopene concentration and TSS.

To further assess the impact of these environmental variables on lycopene and TSS, we used a stepwise regression method. All the regression models were tested for autocorrelation (Durbin-Watson statistic) and multicollinearity. This method allows us to simplify the model equation by including the most important variables affecting the dependent variables (lycopene or TSS). This approach and simplified prediction models may be integrated in a future control algorithm of greenhouse environments. As expected, coefficient of determination of regression $\left(R^{2}\right)$ decreased by reducing the number of variables. The stepwise regression indicated that prediction models for lycopene concentration and TSS could be simplified with EEC as the single independent variable without losing the regression significance. However, $R^{2}$ for lycopene was lower than that for TSS. This is because lycopene develops rapidly during the last few weeks of harvest, which caused more variability among fruit harvested at the same visual ripeness stage. However, determining fruit ripeness stage based on the surface color is a standard commercial procedure to decide harvest timing. Nevertheless, the regression analysis showed that the most important environmental variables used in this study were EEC followed by DT for lycopene [Model (2), Table 2] and DLI for TSS [Model (6)]. The formation of lycopene is known to be largely affected by temperature and was reportedly inhibited when exposed to higher greenhouse temperature (Brandt et al., 2006) or solar radiation causing higher fruit temperature (Dumas et al., 2003; McCollum, 1954). McCollum (1954) showed that illumination enhanced lycopene synthesis when temperature was in a favorable range (22 to $25^{\circ} \mathrm{C}$ ). In our regression analysis, EEC has the strongest influence on lycopene in tomato 
fruit followed by DT (and NT as a result of its high correlation with DT). The light environment (DLI) and VPD were the least influential environmental factors out of the four variables. It would be of interest if high EC treatment could be used as a supplemental tool to maintain high lycopene in lowtemperature conditions. This aspect needs further investigation.

Postharvest quality. There were no significant interactions observed between harvest date (24 Oct. 2005, 10 Mar. 2006, and 28 Aug. 2006) and responses of postharvest quality parameters to storage temperature (data not shown). Therefore, we pooled the fruit quality data of the three harvest dates for analysis.

Weight loss of tomatoes after $10 \mathrm{~d}$ in storage was significantly greater at $20{ }^{\circ} \mathrm{C}$ $(6.7 \%$ loss $)$ and not significantly different between 4 and $12{ }^{\circ} \mathrm{C}(4.7 \%$ loss $)$ regardless of the preharvest EC treatment (Table 3; Fig. 4A). At $20^{\circ} \mathrm{C}$, the weight loss reached nearly $7 \%$, the maximum acceptable loss for tomato according to Kays (1997).

Changes in fruit lycopene concentration over the 10-d storage were affected by storage temperature but the fruit grown under high EC maintained 20.9\% greater lycopene concentration than that under low EC (Table 3; Fig. 4B). No interactions were observed among effects of EC, storage temperature, and duration of time in storage, except for between storage temperature and time (Table 3). At $4{ }^{\circ} \mathrm{C}$, lycopene decreased by $19.2 \%$ regardless of EC (Fig. 4C), presumably as a result of the chilling temperature (Farneti et al., 2012). It is widely known that carotenoid synthesis is affected by chilling stress. At $12{ }^{\circ} \mathrm{C}$, lycopene remained almost unchanged during storage. At $20{ }^{\circ} \mathrm{C}$, lycopene concentration increased by $45.3 \%$ during the 10 -d storage.

Table 1. Pearson's correlations between lycopene concentration ( $\mathrm{mg} \cdot \mathrm{kg}^{-1}$ fresh weight) or total soluble solid concentration (TSS, Brix) and the 4-week running average of daily light integral (DLI), daytime temperature, daytime vapor pressure deficit (VPD), and efflux solution's electrical conductivity (EC) $(\mathrm{n}=3)$.

\begin{tabular}{|c|c|c|c|c|}
\hline & \multicolumn{2}{|c|}{ Lycopene concn $\left(\mathrm{mg} \cdot \mathrm{kg}^{-1} \mathrm{FW}\right)$} & \multicolumn{2}{|c|}{ TSS (Brix) } \\
\hline & $\overline{\text { Correlation coefficient }}$ & $\overline{\text { Significance }}$ & $\overline{\text { Correlation coefficient }}$ & Significance \\
\hline$\overline{\mathrm{DLI}}\left(\mathrm{mol} \cdot \mathrm{m}^{-2}\right)$ & 0.291 & 0.005 & 0.279 & 0.008 \\
\hline mperature $\left({ }^{\circ} \mathrm{C}\right)$ & 0.332 & 0.001 & -0.093 & 0.386 \\
\hline Daytime VPD $(\mathrm{kPa})$ & 0.241 & 0.022 & 0.249 & 0.018 \\
\hline Efflux EC (dS.m $\left.{ }^{-1}\right)$ & 0.500 & $<0.0001$ & 0.712 & $<0.0001$ \\
\hline Lycopene $\left(\mathrm{mg} \cdot \mathrm{kg}^{-1} \mathrm{FW}\right)$ & - & - & 0.413 & $<0.0001$ \\
\hline
\end{tabular}

TSS concentration was strongly affected by EC and duration of time in storage (Table 3 ) and showed a weak significance $(P=0.0747)$ for the interaction between EC and duration of time in storage. The TSS increase over time for $10 \mathrm{~d}$ in storage was minimum $(4.7 \%)$ for the fruit grown under low EC (Fig. 4D), most likely as a result of the water loss from the fruit $(4.7 \%$ to $6.7 \%)$. A trend of relatively stable TSS in storage was also observed by Javanmardi and Kubota (2006) for $7 \mathrm{~d}$ at $12{ }^{\circ} \mathrm{C}$ followed by $5{ }^{\circ} \mathrm{C}$ for $7 \mathrm{~d}$ (total of $14 \mathrm{~d}$ ) and Kagan-Zur and Mizrahi (1993) for $10 \mathrm{~d}$ at $12{ }^{\circ} \mathrm{C}$. In contrast, when grown under high EC, TSS of fruit increased by $14.6 \%$ during $10 \mathrm{~d}$ regardless of temperature. This percent increase was greater than the weight loss, indicating that soluble solids in fruit grown under high EC increased during storage. Dynamics of sugar and organic acid concentrations as affected by storage temperature and duration has been studied by other research groups. Gómez et al. (2009) found that fructose concentration in red ripe fruit of 'Micro-Tom' cherry tomato harvested from plants grown in a growth chamber increased significantly during 15 -d storage $\left(6\right.$ or $20^{\circ} \mathrm{C}$ ), whereas glucose concentration increased at $20^{\circ} \mathrm{C}$ but not at $6{ }^{\circ} \mathrm{C}$. They also found that major organic acids (tartaric, malic, citric, succinic, and ascorbic acids) showed different patterns of changes during storage.

Under high salt stress conditions, several authors suggested that fruit accumulated and allocated more assimilates to starch (Balibrea et al., 1997; Ehret and Ho, 1986; Gao et al., 1998; Heuvelink and Dorais, 2005). Sucrose synthase enzyme was also intensified when plants were cultivated under high salinity (Heuvelink and Dorais, 2005; Ho, 1996). Islam et al. (1995) reported that fruit with greater sugar content (grown under high $\mathrm{CO}_{2}$

$\mathrm{FW}=$ fresh weight. concentration) at the time of harvest (red ripeness stage) had relatively higher activity of acid invertase, which catalyzes the hydrolysis of sucrose to glucose and fructose. As a result, they found that fruit grown under high $\mathrm{CO}_{2}$ concentration ( 700 to $900 \mu \mathrm{mol} \cdot \mathrm{mol}^{-1}$ ) increased sugar concentrations over 15-d storage at $20^{\circ} \mathrm{C}$, whereas fruit grown without $\mathrm{CO}_{2}$ control ( 250 to $400 \mu \mathrm{mol} \cdot \mathrm{mol}^{-1}$ ) remained relatively unchanged. Therefore, based on these reports, the fruit developed under high EC in the present experiment may have had a greater starch reserve at the time of harvest and higher invertase activities during storage than the fruit under low EC, which possibly contributed to increasing TSS after harvest. This possibility needs to be validated by analyzing fruit carbohydrate composition during storage.

Ascorbic acid and total phenolic concentrations at the start of storage experiment were $3.0 \pm 0.09$ and $5.2 \pm 0.16 \mathrm{mg} \cdot \mathrm{g}^{-1}$ dry weight, respectively. There was no significant difference observed in either ascorbic acid or total phenolics between high and low EC treatments. Ascorbic acid concentration during the storage was affected only by duration of time in storage and increased over time in storage (Table 3; Fig. 4E). A similar trend was observed for concentration of total phenolics compounds (Fig. 4F) but to a lesser extent than for ascorbic acid concentration. Javanmardi and Kubota (2006) found that 'Durinta' tomato (the same cultivar in the present experiment) antioxidant activities increased over the $14 \mathrm{~d}$ low-temperature storage $\left(12{ }^{\circ} \mathrm{C}\right.$ followed by $\left.5{ }^{\circ} \mathrm{C}\right)$ and suggested an increase in antioxidants in fruit. Similarly, a slight accumulation of ascorbic acid was observed during storage of tomato harvested at the light-red stage and stored at 7 to $25^{\circ} \mathrm{C}$ temperature (Toor and Savage, 2006). However, ascorbic acid in Gómez et al. (2009) showed a slight decrease over time at 6 and $20{ }^{\circ} \mathrm{C}$. Total phenolic concentration also showed slight increase over time in storage. In contrast, an increase in phenolic compounds was observed for tomato stored at the breaker ripeness stage, but not for the red ripeness stage (Gómez et al., 2009). These discrepancies suggest that changes in ascorbic acid and total phenolic concentrations resulting from secondary metabolism might be highly interacted with preharvest conditions and cultivars. In fact, Kim et al. (2008) showed that changes in phenolic concentration of fresh

Table 2. Regression equations for lycopene concentration (LC, $\mathrm{mg} \cdot \mathrm{kg}^{-1}$ fresh weight) and total soluble solid concentration (TSS, Brix) using a 4-week running average of daily light integral (DLI, $\left.\mathrm{mol} \cdot \mathrm{m}^{-2} \cdot \mathrm{d}^{-1}\right)$, daytime temperature $\left(\mathrm{DT},{ }^{\circ} \mathrm{C}\right)$, daytime vapor pressure deficit $(\mathrm{VPD}$, $\mathrm{kPa})$, and efflux solution's electrical conductivity $\left(\right.$ EEC, $\left.\mathrm{dS} \cdot \mathrm{m}^{-1}\right)$ as independent variables. ${ }^{\mathrm{z}}$

\begin{tabular}{lclc}
\hline Model no. & $\begin{array}{c}\text { Dependent } \\
\text { variables }\end{array}$ & \multicolumn{1}{c}{ Equations } & $R^{2}$ \\
\hline 1 & LC & LC $=19.2+0.285$ DLI + 0.774 DT + 0.928 VPD + 1.65 EEC & 0.399 \\
2 & LC & LC $=18.7+1.12$ DT + 1.64 EEC & 0.377 \\
3 & LC & LC $=44.3+1.58$ EEC & $<.250$ \\
4 & TSS & TSS $=3.97+0.060$ DLI -0.124 DT +1.23 VPD +0.164 EEC & $<0.0001$ \\
5 & TSS & TSS $=4.08+0.061$ DLI -0.079 DT +0.171 EEC & $<0.0001$ \\
6 & TSS & TSS $=2.77+0.038$ DLI + 0.172 EEC & 0.774 \\
7 & TSS & TSS $=3.64+0.168$ EEC & $<0.0001$ \\
\hline
\end{tabular}

${ }^{2}$ Coefficient of determination $\left(R^{2}\right)$ and the significance ( $P$ value) was computed by a stepwise regression analysis. 
Table 3. Significance of main factors and their interactions on weight loss, lycopene, total soluble solid concentration (TSS), ascorbic acid, and total phenolic concentrations during 10-d storage. ${ }^{z}$

\begin{tabular}{lrrrrc}
\hline Factors & Wt loss & $\begin{array}{c}\text { Lycopene } \\
\text { concn }\end{array}$ & \multicolumn{1}{c}{ TSS } & $\begin{array}{c}\text { Ascorbic acid } \\
\text { concn }\end{array}$ & $\begin{array}{c}\text { Total phenolics } \\
\text { concn }\end{array}$ \\
\hline EC & 0.1289 & $<0.0001$ & $<0.0001$ & 0.1531 & 0.4539 \\
Storage temperature (T) & $<0.0001$ & $<0.0001$ & 0.8189 & 0.8034 & 0.3239 \\
Days in storage (D) & $<0.0001$ & $<0.0001$ & $<0.0007$ & 0.0228 & 0.0004 \\
EC $\times$ T & 0.4740 & 0.2810 & 0.7783 & 0.9572 & 0.9832 \\
EC $\times$ D & 0.2259 & 0.6947 & 0.0747 & 0.2896 & 0.1543 \\
$\mathrm{~T} \times \mathrm{D}$ & 0.7036 & $<0.0001$ & 0.9630 & 0.9987 & 0.7158 \\
$\mathrm{EC} \times \mathrm{T} \times \mathrm{D}$ & 0.6748 & 0.9507 & 0.9798 & 0.9408 & 0.9590 \\
\hline
\end{tabular}

${ }^{\mathrm{z}}$ Analysis of variance (ANOVA) was applied for the pooled data out of three harvest dates (24 Oct. 2005; 10 Mar. 2006; and 28 Aug. 2006) $(\mathrm{n}=9)$.
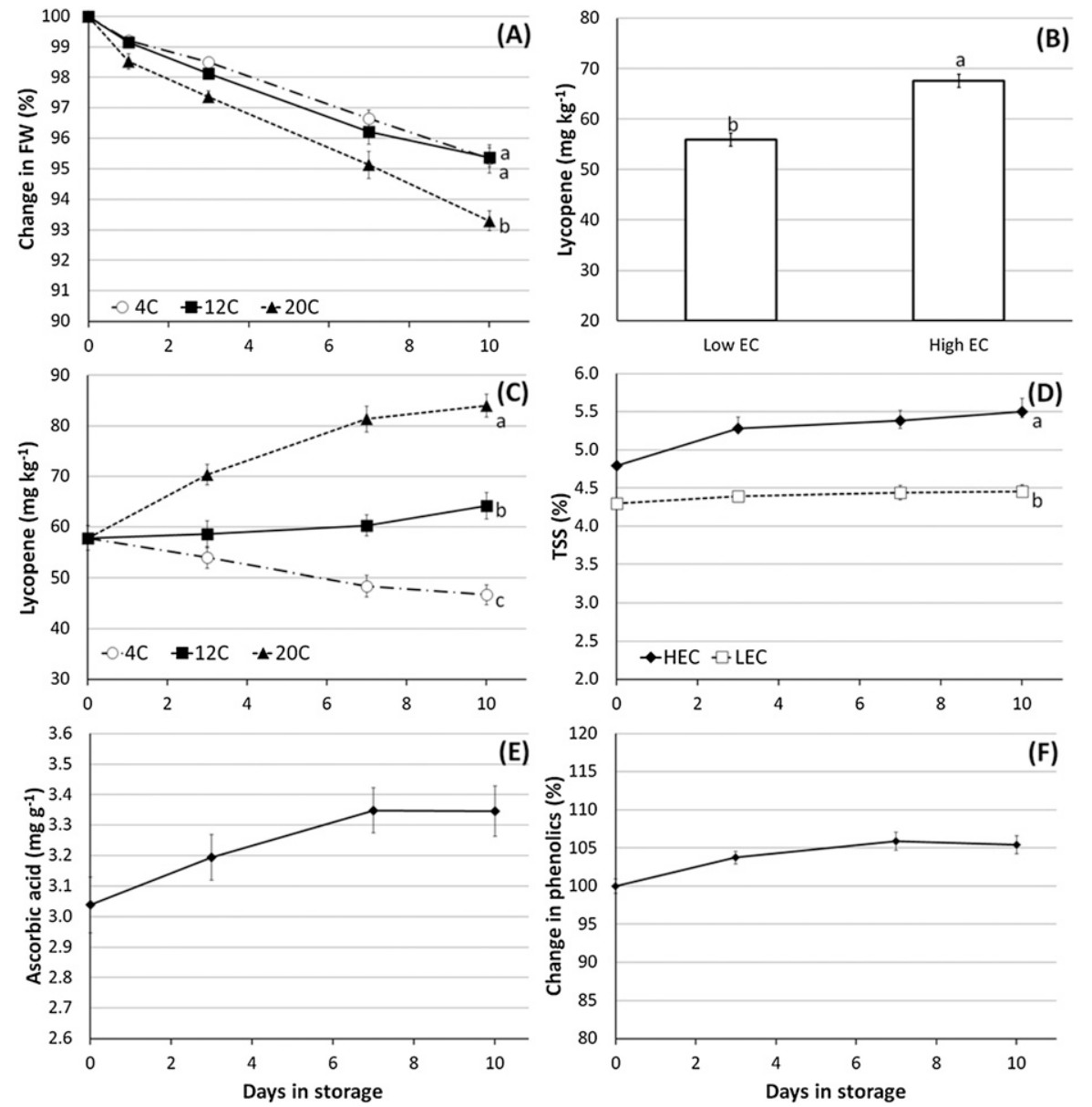

Fig. 4. Effects of (A) storage temperature and time (days) on weight loss (percent of fresh weight on Day 0 , the start of storage) (averages of EC treatments, $\mathrm{n}=18),(\mathbf{B})$ preharvest EC treatment on lycopene concentration during storage $\left(\mathrm{mg} \cdot \mathrm{kg}^{-1}\right.$ fresh weight) (averages of temperature treatments at four observations, $\mathrm{n}=108),(\mathbf{C})$ storage temperature and time on lycopene concentration during storage (mg. $\mathrm{kg}^{-1}$ fresh weight) (averages of EC treatments, $\left.\mathrm{n}=18\right),(\mathbf{D})$ preharvest $\mathrm{EC}$ treatment and storage time on TSS (\% Brix) (averages of temperature treatments, $\mathrm{n}=27)$, and storage time on $(\mathbf{E})$ ascorbic acid concentration (mg. $\mathrm{g}^{-1}$ dry weight) (averages of all treatments, $\mathrm{n}=54$ ) and $(\mathbf{F})$ relative total phenolics concentration (\%) (averages of all treatments, $\mathrm{n}=54$ ) in fruit harvested at the red ripeness stage. Main factors significance and their interactions are summarized in Table 3. The total phenolic concentration was expressed relative to the concentration at the time of harvest (Day 0) and analyzed after arsine of square root transformation as a result of a technical issue with the gallic acid standard. Means \pm SE are shown with separation by honestly significant difference test $(P<0.01) . \mathrm{EC}=$ electrical conductivity.

cut tomato were highly affected by the preharvest, nutrient solution EC.

\section{Conclusion}

The present research demonstrated yearround production of tomatoes with increased levels of lycopene concentration and TSS. for lycopene concentration and DLI for TSS. These elevated lycopene concentration and TSS influenced by the preharvest conditions remained unchanged for $10 \mathrm{~d}$ at $12{ }^{\circ} \mathrm{C}$ storage temperature, the most widely accepted storage temperature for tomato. Ascorbic acid and phenolic concentrations exhibited a slight increase over time during the storage regardless of storage temperature or preharvest EC treatments. Overall, producing lycopene-rich tomato by controlling $\mathrm{EC}$ of nutrient solution was shown to be feasible during year-round greenhouse production using a high-wire rockwool culture system.

\section{Literature Cited}

Adams, P. 1991. Effects of increasing the salinity of the nutrient solution with major nutrients or sodium chloride on the yield, quality and composition of tomato grown in rockwool. J. Hort. Sci. 66:201-207.

Balibrea, M.E., E. Cayuela, F. Artés, and F. PérezAlfocea. 1997. Salinity effects on some postharvest quality factors in a commercial tomato hybrid. J. Hort. Sci. 72:885-892.

Böhm, V. 2012. Lycopene and heart health. Mol. Nutr. Food Res. 56:296-303.

Brandt, S., Z. Pék, É. Barna, A. Lugasi, and L. Helyes. 2006. Lycopene content and color of ripening tomatoes as affected by environmental conditions. J. Sci. Food Agr. 86:568-572.

Buck, J.S., C. Kubota, and M. Jensen. 2008. Effect of mid-day reduction of high electrical conductivity treatment on the yield and quality of greenhouse cherry tomato. HortTechnology 18: 460-466.

Cook, R. and L. Calvin. 2005. Greenhouse tomatoes change the dynamics of the North American Fresh Tomato Industry. USDA Economic Research Report No. 2. <http://www.ers.usda.gov/ publications/err2/>

Dorais, M., A.P. Papadopoulos, and A. Gosselin. 2001. Influence of electric conductivity management on greenhouse tomato yield and fruit quality. Agronomie 21:367-383.

Dumas, Y., M. Dadomo, G. Di Lucca, and P. Grolier. 2003. Effects of environmental factors and agricultural techniques on antioxidant content of tomatoes. J. Sci. Food Agr. 83:369-382.

Ehret, D.L. and L.C. Ho. 1986. The effect of salinity on dry matter partitioning and fruit growth in tomatoes grown in nutrient film culture. J. Hort. Sci. 61:361-367.

FAO. 2011. FAOSTAT 2009 data. Food and Agricultural Organization. $<$ http://faostat.fao. org/site/567/default.aspx\#ancor>.

Farneti, B., R.E. Schouten, and E.J. Woltering. 2012. Low temperature-induced lycopene degradation in red ripe tomato evaluated by remittance spectroscopy. Postharvest Physiol. Biol. 73:22-27.

Fish, W., P. Perkins-Veazie, and J. Collins. 2002. A quantitative assay for lycopene that utilizes reduced volumes of organic solvents. J. Food Compost. Anal. 15:309-317.

Gao, Z., M. Sagi, and S.H. Lips. 1998. Carbohydrate metabolism in leaves and assimilate partitioning in fruits of tomato (Lycopersicon esculentum L.) as affected by salinity. Plant Sci. 135:149-159.

Giovanelli, G., V. Lavelli, C. Peri, and S. Nobili. 1999. Variation in antioxidant components of tomato during vine and post-harvest ripening. J. Sci. Food Agr. 79:1583-1588.

Gómez, P., M.Á. Ferrer, J.P. Fernández-Trujillo, A. Calderón, F. Artés, M. Egea-Cortines, and 
J. Weiss. 2009. Structural changes, chemical composition and antioxidant activity of cherry tomato fruits (cv. Micro-Tom) stored under optimal and chilling conditions. J. Sci. Food Agr. 89:1543-1551.

Heuvelink, E. and M. Dorais. 2005. Crop growth and yield, p. 85-144. In: Heuvelink, E. (ed.). Tomatoes. CAB International, Cambridge, MA.

Higashide, T. 2009. Prediction of tomato yield on the basis of solar radiation before anthesis under warm greenhouse conditions. HortScience 44:1874-1878.

Higashide, T. and E. Heuvelink. 2009. Physiological and morphological changes over the past 50 years in yield components in tomato. J. Amer. Soc. Hort. Sci. 134:460-465.

Ho, L.C. 1996. Tomato, p. 709-728. In: Zamski, E. and A.A. Schaffer (eds.). Photoassimilate distribution in plants and crops: Source-sink relationships. Marcel Dekker, New York, NY.

Islam, M.S., T. Matsui, and Y. Yoshida. 1995. Effect of preharvest carbon dioxide enrichment on the post-harvest quality of tomatoes. J. Jpn. Soc. Hort. Sci. 64:649-655.

Javanmardi, J. and C. Kubota. 2006. Variation of lycopene, antioxidant activity, total soluble solids and weight loss of tomato during postharvest storage. Postharvest Biol. Technol. 41:151-155.

Kagan-Zur, V. and Y. Mizrahi. 1993. Long shelflife small sized (cocktail) tomatoes may be picked in bunches. Sci. Hort. 56:31-41.

Kays, S.J. 1997. Postharvest physiology of perishable plant products. Exon Press, Athens, GA.

Kelkel, M., M. Schumacher, M. Dicato, and M. Diederich. 2011. Antioxidant and anti-proliferative properties of lycopene. Free Radic. Res. 45:925940.

Kim, H.-J., J.M. Fonseca, J.-H. Choi, and C. Kubota. 2007. Effect of hydrogen peroxide on quality of fresh-cut tomato. J. Food Sci. 72:463-467.

Kim, H.J., J.M. Fonseca, C. Kubota, M. Kroggel, and J.H. Choi. 2008. Quality of fresh-cut tomatoes as affected by salt content in irrigation water and post-processing ultraviolet-C treatment. J. Sci. Food Agr. 88:1969-1974.

Krauss, S., W.H. Schnitzler, J. Grassmann, and M. Woitke. 2006. The influence of different electrical conductivity values in a simplified recirculation soilless system on inner and outer fruit quality characteristics of tomato. J. Agr. Food Chem. 54:441-448.

Krumbein, A., D. Schwarz, and H.-P. Klaring. 2006. Effects of environmental factors on carotenoid content in tomato [Lycopersicon esculentum (L.) Mill.] grown in a greenhouse. J. Appl. Bot. Food Qual. 80:160-164.

Kubota, C., C.A. Thomson, M. Wu, and J. Javanmardi. 2006. Controlled environments for production of value-added food crops with high phytochemical concentrations: High lycopene tomato as an example. HortScience 41:522-525.

Liu, L.H., D. Zabaras, L.E. Bennett, P. Aguas, and B.W. Woonton. 2009. Effects of UV-C, red light and sun light on the carotenoid content and physical qualities of tomatoes during postharvest storage. Food Chem. 115:495-500.

McCollum, J.P. 1954. Effects of light on the formation of carotenoids in tomato fruits. Food Res. 19:182-189.
Saltveit, M.E. 2005. Fruit ripening and fruit quality, p. 145-170. In: Heuvelink, E. (ed.). Tomatoes. CAB International, Cambridge, MA.

Tanaka, T., M. Shimizu, and H. Moriwaki. 2012. Cancer chemoprevention by carotenoids. Molecules 17:3202-3242.

Thomson, C.A., N.R. Stendell-Hollis, J.L. West, E.C. Cussler, L.M. McCune, M. Kroggel, H.J. Kim, and C. Kubota. 2008. High-lycopene consumption increases serum carotenoid levels but does not have decrease levels of oxidative stress and inflammation in healthy adults. The Open Bioactive Compounds Journal. 1:7-12.

Toor, R.K. and G.P. Savage. 2006. Changes in major antioxidant components of tomatoes during postharvest storage. Food Chem. 99: 724-727.

Weaver, R.D., D.J. Evans, and A.E. Luloff. 1992. Pesticide use in tomato production: Consumer concerns and willingness-to-pay. Agribusiness $8: 131-142$.

Wills, R.B.H. and V.V.V. Ku. 2002. Use of 1-MCP to extend the time to ripen of green tomatoes and postharvest life of ripe tomatoes. Postharvest Biol. Technol. 26:85-90.

Wismer, W.V. 2009. Consumer eating habits and perceptions of fresh produce quality, p. 23-42. In: Florkowski, W.J., R.L. Shewfelt, B. Brueckner, and S.E. Prussia (eds.). Postharvest handling. A systems approach. Academic Press.

Wu, M. and C. Kubota. 2008. Effects of high electrical conductivity of nutrient solution and its application timing on lycopene, chlorophyll and sugar concentrations of hydroponic tomatoes during ripening. Sci. Hort. 116:122-129. 